Cochrane Database of Systematic Reviews

\title{
Carbohydrate supplementation of human milk to promote growth in preterm infants (Review)
}

Amissah EA, Brown J, Harding JE

Amissah EA, Brown J, Harding JE.

Carbohydrate supplementation of human milk to promote growth in preterm infants.

Cochrane Database of Systematic Reviews 2018, Issue 8. Art. No.: CD000280.

DOI: 10.1002/14651858.CD000280.pub2.

www.cochranelibrary.com 
TABLE OF CONTENTS

HEADER

ABSTRACT

PLAIN LANGUAGE SUMMARY

SUMMARY OF FINDINGS

BACKGROUND

OBJECTIVES

METHODS

RESULTS

Figure 1.

Figure 2.

Figure 3.

DISCUSSION

AUTHORS' CONCLUSIONS

ACKNOWLEDGEMENTS

REFERENCES

CHARACTERISTICS OF STUDIES

DATA AND ANALYSES

Analysis 1.1. Comparison 1 Carbohydrate supplementation versus control, Outcome $1 \mathrm{Growth} /$ Weight.

Analysis 1.2. Comparison 1 Carbohydrate supplementation versus control, Outcome 2 Feeding intolerance.

Analysis 1.3. Comparison 1 Carbohydrate supplementation versus control, Outcome 3 Necrotising enterocolitis.

WHAT'S NEW

HISTORY

CONTRIBUTIONS OF AUTHORS

DECLARATIONS OF INTEREST

SOURCES OF SUPPORT

DIFFERENCES BETWEEN PROTOCOL AND REVIEW

INDEX TERMS 
[Intervention Review]

\section{Carbohydrate supplementation of human milk to promote growth in preterm infants}

Emma A Amissah¹, Julie Brown², Jane E Harding1

1Liggins Institute, University of Auckland, Auckland, New Zealand. 2Department of Obstetrics and Gynaecology, The University of Auckland, Auckland, New Zealand

Contact address: Jane E Harding, Liggins Institute, University of Auckland, Auckland, New Zealand. j.harding@auckland.ac.nz.

Editorial group: Cochrane Neonatal Group

Publication status and date: New search for studies and content updated (conclusions changed), published in Issue 8, 2018.

Citation: Amissah EA, Brown J, Harding JE. Carbohydrate supplementation of human milk to promote growth in preterm infants. Cochrane Database of Systematic Reviews 2018, Issue 8. Art. No.: CD000280. DOI: 10.1002/14651858.CD000280.pub2.

Copyright @ 2018 The Cochrane Collaboration. Published by John Wiley \& Sons, Ltd.

\section{A B S T R A C T}

\section{Background}

Preterm infants are born with low glycogen stores and require higher glucose intake to match fetal accretion rates. In spite of the myriad benefits of breast milk for preterm infants, it may not adequately meet the needs of these rapidly growing infants. Supplementing human milk with carbohydrates may help. However, there is a paucity of data on assessment of benefits or harms of carbohydrate supplementation of human milk to promote growth in preterm infants. This is a 2018 update of a Cochrane Review first published in 1999.

\section{Objectives}

To determine whether human milk supplemented with carbohydrate compared with unsupplemented human milk fed to preterm infants improves growth, body composition, and cardio-metabolic and neurodevelopmental outcomes without significant adverse effects.

\section{Search methods}

We used the standard search strategy of the Cochrane Neonatal Review Group to search the Cochrane Central Register of Controlled Trials (CENTRAL; 2017, Issue 8), MEDLINE via PubMed (1966 to 21 February 2018), Embase (1980 to 21 February 2018), and the Cumulative Index to Nursing and Allied Health Literature (CINAHL; 1982 to 21 February 2018). We also searched clinical trials databases, conference proceedings, and reference lists of retrieved articles for randomised controlled trials (RCTs) and quasi-randomised trials.

\section{Selection criteria}

Published and unpublished controlled trials were eligible if they used random or quasi-random methods to allocate preterm infants in hospital fed human milk to supplementation or no supplementation with additional carbohydrate.

\section{Data collection and analysis}

Two review authors independently abstracted data and assessed trial quality and the quality of evidence at the outcome level using the Grading of Recommendations Assessment, Development and Evaluation (GRADE) method. We planned to perform meta-analyses using risk ratios (RRs) for dichotomous data and mean differences (MDs) for continuous data, with their respective 95\% confidence intervals (Cls). We planned to use a fixed-effect model and to explore potential causes of heterogeneity via sensitivity analyses. We contacted study authors for additional information.

\section{Main results}

One unblinded, quasi-randomised controlled trial (RCT) assessing effects of carbohydrate supplementation of human milk in the form of a prebiotic in 75 preterm infants was eligible for inclusion in this review. We identified two publications of the same trial, which reported different methods regarding blinding and randomisation. Study authors confirmed that these publications pertain to the same trial, but 
they have not yet clarified which method is correct. We were unable to reproduce analyses from the data presented. At 30 days of age, the mean weight of preterm infants in the trial was greater in the prebiotic carbohydrate-supplemented group than in the unsupplemented group (MD 160.4 grams, $95 \% \mathrm{Cl} 12.4$ to 308.4 grams; one RCT, $\mathrm{N}=75$; very low-quality evidence). We found no evidence of a clear difference in risk of feeding intolerance (RR $0.64,95 \% \mathrm{Cl} 0.36$ to 1.15; one RCT, $\mathrm{N}=75$ infants; very low-quality evidence) or necrotising enterocolitis (NEC) (RR 0.2, 95\% Cl 0.02 to 1.3; one RCT, $\mathrm{N}=75$ infants; very low-quality evidence) between the prebiotic-supplemented group and the unsupplemented group. Duration of hospital stay was shorter in the prebiotic group than in the control group at a median (range) of 16 ( 9 to 45 ) days ( $95 \% \mathrm{Cl} 15.34$ to 24.09$)$ and 25 (11 to 80 ) days ( $95 \% \mathrm{Cl} 25.52$ to 34.39), respectively. No other data were available for assessing effects of carbohydrate supplementation on short- and long-term growth, body mass index, body composition, and neurodevelopmental or cardio-metabolic outcomes.

\section{Authors' conclusions}

We found insufficient evidence on the short- and long-term effects of carbohydrate supplementation of human milk in preterm infants. The only trial included in this review presented very low-quality evidence, and study authors provided uncertain information about study methods and analysis. The evidence may be limited in its applicability because researchers included a small sample of preterm infants from a single centre. However, the outcomes assessed are common to all preterm infants, and this trial demonstrates the feasibility of prebiotic carbohydrate supplementation in upper-middle-income countries. Future trials should assess the safety and efficacy of different types and concentrations of carbohydrate supplementation for preterm infants fed human milk. Although prebiotic carbohydrate supplementation in preterm infants is currently a topic of active research, we do not envisage that further trials of digestible carbohydrates will be conducted, as this is currently done as a component of multi-nutrient human milk fortification. Hence we do not plan to publish any further updates of this review.

\section{PLAIN LANGUAGE SUMMARY}

\section{Carbohydrate supplementation of human milk to promote growth in preterm infants}

\section{Review question}

Does addition of extra carbohydrate to human milk fed to preterm infants compared with no additional carbohydrate improve growth, body fat, obesity, heart problems, high blood sugar, and brain development without causing significant side effects?

\section{Background}

Not enough carbohydrate intake in preterm infants may result in poor growth and development. Breast milk is the best food for preterm infants, but feeding them only breast milk may be nutritionally inadequate. Adding carbohydrate to breast milk may help. However, not enough data can be found on assessing the benefits and harms of adding carbohydrate to breast milk to promote growth in preterm infants.

\section{Study characteristics}

We found one trial involving 75 preterm infants with very low-quality evidence on the effects of adding extra prebiotics (a type of carbohydrate) to human milk in preterm infants. A second publication by the same study authors reported different methods regarding blinding and randomisation of the trial. Study authors confirmed that these publications describe the same trial but have not yet clarified which method is accurate. We were unable to reproduce the analyses from the data presented. The search is up-to-date as of February 2018.

\section{Key results}

Prebiotic carbohydrate supplementation increased the mean weight of preterm infants at day 30 and resulted in a shorter hospital stay compared with control. No evidence shows a clear difference in risk of feeding intolerance or necrotising enterocolitis between the prebiotic-supplemented and unsupplemented groups. No other data were available to show the effects of adding extra carbohydrate to human milk on short- and long-term growth, body fat, obesity, brain development, and heart problems.

\section{Conclusions}

Evidence on the short- and long-term effects of adding extra carbohydrate to human milk in preterm infants is lacking. This systematic review found very low-quality evidence on the effects of adding prebiotic carbohydrate to human milk in preterm infants, along with uncertainties about methods and analysis. The single trial included a small sample of Iranian preterm infants, and so the evidence may be considered as not generalisable. However, the outcomes assessed are common to all preterm infants, and the trial shows that adding prebiotic carbohydrate to human milk is possible in developing countries. Further research is needed to assess the benefits and harms of different types and concentrations of carbohydrate supplementation for preterm infants fed human milk. Currently, digestible carbohydrate supplementation in preterm infants is provided as a component of multi-nutrient human milk fortification. Hence we do not plan to publish further updates of this review. 


\begin{tabular}{|c|c|c|c|c|c|c|c|}
\hline \multirow{10}{*}{ 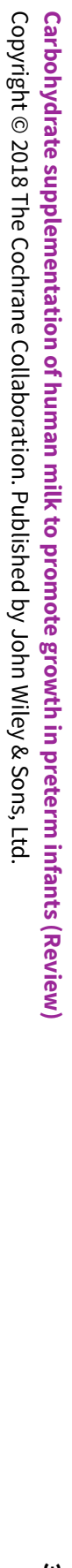 } & \multicolumn{7}{|c|}{$\begin{array}{l}\text { S U M M A R Y O F F I N D I N G S } \\
\text { Summary of findings for the main comparison. Carbohydrate supplementation compared to control in preterm infants }\end{array}$} \\
\hline & \multicolumn{7}{|c|}{ Carbohydrate supplementation compared to control in preterm infants } \\
\hline & \multicolumn{7}{|c|}{$\begin{array}{l}\text { Patient or population: preterm infants } \\
\text { Setting: tertiary neonatal units of Alzahra and Shahid Beheshti Hospital in Iran } \\
\text { Intervention: carbohydrate (prebiotic) supplementation } \\
\text { Comparison: no carbohydrate (prebiotic) supplementation }\end{array}$} \\
\hline & \multirow[t]{2}{*}{ Outcomes } & \multicolumn{2}{|c|}{$\begin{array}{l}\text { Anticipated absolute effects* } \\
(95 \% \mathrm{CI})\end{array}$} & \multirow{2}{*}{$\begin{array}{l}\text { Relative ef- } \\
\text { fect } \\
(95 \% \mathrm{CI})\end{array}$} & \multirow{2}{*}{$\begin{array}{l}\text { № of partici- } \\
\text { pants } \\
\text { (studies) }\end{array}$} & \multirow{2}{*}{$\begin{array}{l}\text { Certainty of } \\
\text { the evidence } \\
\text { (GRADE) }\end{array}$} & \multirow[t]{2}{*}{ Comments } \\
\hline & & $\begin{array}{l}\text { Risk with } \\
\text { control }\end{array}$ & $\begin{array}{l}\text { Risk with car- } \\
\text { bohydrate } \\
\text { supplemen- } \\
\text { tation }\end{array}$ & & & & \\
\hline & $\begin{array}{l}\text { Growth/ } \\
\text { Weight at day } \\
30\end{array}$ & $\begin{array}{l}\text { Mean weight } \\
1542.4 \mathrm{~g}\end{array}$ & $\begin{array}{l}\text { Mean weight } \\
\text { increased by } \\
160.4 \mathrm{~g} \\
(12.4 \text { to } 308.4)\end{array}$ & - & 75 (1 RCT) & $\begin{array}{l}\oplus \odot \Theta \odot \\
\text { Very lowa,b,c }\end{array}$ & $\begin{array}{l}\text { No other data were reported on growth except for weight at day } \\
30 .\end{array}$ \\
\hline & $\begin{array}{l}\text { Neurodevel- } \\
\text { opmental out- } \\
\text { comes }\end{array}$ & - & - & - & - & - & No data were reported for this outcome in the included trial. \\
\hline & $\begin{array}{l}\text { Duration of } \\
\text { hospital stay }\end{array}$ & - & - & - & $\begin{array}{l}75 \\
(1 \mathrm{RCT})\end{array}$ & $\begin{array}{l}\oplus \odot \odot \odot \\
\text { Very lowa,b,c }\end{array}$ & $\begin{array}{l}\text { The trial reported data on duration of hospital stay using medi- } \\
\text { an (range) for the prebiotic-supplemented and unsupplemented } \\
\text { groups as } 16 \text { ( } 9 \text { to } 45 \text { ) ( } 95 \% \mathrm{Cl} 15.34 \text { to } 24.09 \text { days) and } 25 \text { ( } 11 \text { to } 80 \text { ) } \\
\text { ( } 95 \% \mathrm{Cl} 25.52 \text { to } 34.39 \text { days), respectively. We have reported this } \\
\text { outcome in the text of the review. }\end{array}$ \\
\hline & $\begin{array}{l}\text { Feeding Intol- } \\
\text { erance }\end{array}$ & 560 per 1000 & $\begin{array}{l}358 \text { per } 1000 \\
(202 \text { to } 644)\end{array}$ & $\begin{array}{l}\text { RR } 0.64 \\
(0.36 \text { to } 1.15)\end{array}$ & $\begin{array}{l}75 \\
(1 \mathrm{RCT})\end{array}$ & $\begin{array}{l}\oplus \Theta \Theta \Theta \\
\text { Very lowa,b,c }\end{array}$ & $\begin{array}{l}\text { Study authors defined feeding intolerance as "gastric residue, i.e. } \\
\text { the presence of milk in the stomach two hours after completion of } \\
\text { a feeding". However another reported outcome was "requiring to } \\
\text { cut off milk", which was similar to our pre-specified definition of } \\
\text { feeding intolerance, i.e. resulting in cessation or reduction in en- } \\
\text { teral feeding. Thus, we used "requiring to cut off milk" in the analy- } \\
\text { sis of feeding intolerance. }\end{array}$ \\
\hline & $\begin{array}{l}\text { Necrotising } \\
\text { enterocolitis }\end{array}$ & 220 per 1000 & $\begin{array}{l}40 \text { per } 1000 \\
(4 \text { to } 293)\end{array}$ & $\begin{array}{l}\text { RR } 0.18 \\
(0.02 \text { to } 1.3)\end{array}$ & $\begin{array}{l}75 \\
(1 \mathrm{RCT})\end{array}$ & $\oplus \odot \odot \odot$ & $\begin{array}{l}\text { Definition was suspected NEC, which was based on clinical assess- } \\
\text { ment }\end{array}$ \\
\hline
\end{tabular}


*The risk in the intervention group (and its 95\% confidence interval) is based on the assumed risk in the comparison group and the relative effect of the intervention (and its $95 \% \mathrm{Cl})$.

Cl: confidence interval; RCT: randomised controlled trial; RR: risk ratio.

\section{GRADE Working Group grades of evidence}

High certainty: we are very confident that the true effect lies close to that of the estimate of the effect.

Moderate certainty: we are moderately confident in the effect estimate: the true effect is likely to be close to the estimate of the effect, but there is a possibility that it is

substantially different.

Low certainty: our confidence in the effect estimate is limited: the true effect may be substantially different from the estimate of the effect.

Very low certainty: we have very little confidence in the effect estimate: the true effect is likely to be substantially different from the estimate of effect.

aRisk of bias: the trial lacked methodological details and caregivers were not blinded. This could have an impact on assessment of feeding intolerance and possibly the estimate of effect. Downgraded one level

Indirectness: we did not get any response from study authors for clarification on dosage, frequency, and duration of administration of the enteral prebiotic. However, it appears

from the publication that only a single dose of $1.5 \mathrm{~g} / \mathrm{kg} / \mathrm{d}$ of the prebiotic supplement was given mixed with breast milk for a day or two. We downgraded this one level.

Imprecision: small sample size, few events, and wide confidence intervals. Downgraded two levels 


\section{B A C K G R O U N D}

\section{Description of the condition}

Infants born preterm have low glycogen reserves because they are born before the phase of rapid glycogen accumulation in the third trimester of pregnancy (Velaphi 2011). To compensate for prenatal and postnatal deficits, and to match fetal accretion rates, preterm infants require higher glucose intakes and have higher glucose synthetic rates than full-term infants (Fenton 2013). For example, the rate of glucose synthesis among preterm infants at 28 weeks' gestation is 6 to $8 \mathrm{mg} / \mathrm{min} / \mathrm{kg}$ compared to 3 to $5 \mathrm{mg} / \mathrm{min} / \mathrm{kg}$ in fullterm infants (Hay 2008).

Lactose, the most abundant carbohydrate in human milk, is the least variable among milk macronutrients (Ballard 2013). However, its concentration decreases in human milk with decreasing gestational age (Mahajan 2017). Lactose facilitates the absorption of two essential minerals - calcium and magnesium (Gregory 2005; Martin 2016), and it provides about $40 \%$ of the caloric intake of preterm infants (Elzouki 2012). Lactose is a disaccharide that is metabolised in the small intestine by brush border lactase to glucose and galactose (Cowett 2012). Of these two metabolites, glucose is the main endogenous substrate for energy production in the brain, and galactose is essential for the production of galactolipids, which are required for the infant's brain development (Elzouki 2012).

Human milk oligosaccharides (HMOs), the second most abundant carbohydrate in human milk, function as immunological agents (prebiotics) to promote the growth of selective commensal gut bacteria (Ballard 2013). They exhibit anti-infective properties by serving as soluble decoys that alter bacterial adhesion to intestinal walls (Jantscher-Krenn 2012), thereby reducing the risk of sepsis. Specific HMOs act to enhance gastrointestinal immunity and decrease the risk of necrotising enterocolitis (NEC) (Bode 2012). Insufficient consumption of these carbohydrates by the preterm infant may, therefore, have adverse effects on growth, intestinal colonisation, immune maturation, and neurological functioning (Morrow 2011).

Human milk, the ideal enteral nutrition for preterm infants, optimises neurodevelopmental outcomes (Belfort 2016). It decreases the incidence of non-specific gastrointestinal tract infections by $64 \%$ (Duijts 2010), and it reduces the incidence of NEC by $77 \%$, compared with cow's milk-based infant formula (Sullivan 2010). Human milk feeding is associated with fewer rehospitalisations in the first year of life (Vohr 2006), and unlike infant formula, human milk contains a wide range of HMOs (Bode 2012).

However, in spite of its numerous benefits, unsupplemented human milk may not meet the nutritional needs of preterm infants. First, its HMO content is variable. It shows intraindividual and interindividual variations (Blank 2012), and it varies according to maternal genetics (i.e. secretor and Lewis blood group status) and by stage of lactation. HMO concentration is highest in colostrum and decreases with lactational changes from transitional to mature milk (Bode 2012; Gabrielli 2011).

Second, the developmental deficiency of the lactase enzyme in preterm infants may interfere with complete digestion of lactose from breast milk (Ayede 2011). For instance, infants born at between 28 and 34 gestational weeks have only $30 \%$ of the lactase activity of term infants (Fanaroff 2012). This deficiency could limit their ability to maximally derive energy from lactose in breast milk for optimal growth (Blackburn 2017). Although this inefficiency of dietary energy utilisation is salvageable in the colon through fermentation of undigested lactose, some of the energy is lost as heat (Erasmus 2002).

Therefore, for preterm infants who need larger amounts of energy and carbohydrate, carbohydrate supplements are sometimes added to human milk.

\section{Description of the intervention}

Carbohydrate supplements occur as monosaccharides, disaccharides, oligosaccharides, or polysaccharides. They may be derived from cow's milk, human milk, or soy milk or may be synthetically made. They are commercially available as modular supplements or as components of multi-nutrient supplements in liquid or powder form. Carbohydrate supplements may also be found in mixed forms designed to achieve an intended effect (e.g. a disaccharide/polysaccharide mix of glucose polymers and lactose to enhance carbohydrate absorption because of concerns about limited lactase activity in preterm infants) (Duggan 2008). Glucose polymers provide high caloric densities without increasing the osmotic load (Hay 2017), and unlike lactose, they are better absorbed, as they do not require lactase for digestion but are dependent on glucoamylase, which is available in sufficient quantities (Cowett 2012). However, in preterm infants, it is recommended that lactose should account for $40 \%$ to $100 \%$ of the carbohydrate intake (Klein 2002), as it is needed to aid mineral absorption and to foster prebiotic and lactase activities (Blackburn 2017).

Carbohydrate supplements are fed enterally to preterm infants once they begin to tolerate breast milk feeds. Like other macronutrients, they are commonly administered as a fixed dose per unit volume of breast milk, also known as 'standardised fortification' (Mangili 2017).

\section{How the intervention might work}

Carbohydrate digestion in the preterm infant is dependent on the composition of the carbohydrate ingested, the functional maturity of intestinal hydrolytic enzymes, and the gastrointestinal system (Elzouki 2012). Unlike other hydrolytic enzymes such as glucoamylase, which are embedded deeper in villus enterocytes, lactase is located at the tips of intestinal villi, making it vulnerable to intestinal mucosal injury (Duggan 2008). Thus, carbohydrate supplementation is expected to increase concentrations of carbohydrate in human milk and may increase mucosal uptake in cases of intestinal injury (Blackburn 2017). Higher concentrations of carbohydrate fed to preterm infants increase caloric density and thus could contribute to faster growth (Brown 2014).

\section{Why it is important to do this review}

Carbohydrate supplementation of human milk could enhance the optimal growth and health of preterm infants. However, it confers potential risks. For example, excessive intake may result in hyperglycaemia and transient symptoms of malabsorption including diarrhoea, flatulence, abdominal distension, and pain (Heine 2017). Thus, a systematic review of available evidence on the efficacy and safety of carbohydrate supplements in preterm infants is needed to clarify the uncertainties surrounding this intervention. 
This is an update of a previously published Cochrane Review (Kuschel 2000).

\section{O B JE C T IVES}

To determine whether human milk supplemented with carbohydrate compared with unsupplemented human milk fed to preterm infants improves growth, body composition, and cardiometabolic and neurodevelopmental outcomes without causing significant adverse effects.

\section{METHODS}

\section{Criteria for considering studies for this review}

\section{Types of studies}

We considered published and unpublished controlled trials utilising random or quasi-random patient allocation for inclusion in this review. We excluded cross-over trials.

\section{Types of participants}

Preterm infants ( $<37$ weeks' gestation) receiving enteral feeding of human milk within a hospital setting.

\section{Types of interventions}

Human milk with or without additional carbohydrate supplementation.

\section{Types of outcome measures}

Primary and secondary outcomes for this review were aligned with the outcomes of the Cochrane Review titled "Multi-nutrient fortification of human milk for preterm infants" (Brown 2016).

\section{Primary outcomes}

- Growth: weight, length, head circumference, skinfold thickness, body mass index, and measures of body composition (lean/ fat mass) and growth restriction (proportion of infants who remain $<10$ th percentile for the index population distribution for weight, length, or head circumference)

* Researchers assessed growth parameters from birth to hospital discharge, at or after two years' corrected age, during adolescence, and during adulthood

- Neurodevelopmental outcomes

- Neurodevelopmental outcomes after 12 months post term included neurological evaluations, developmental scores, and classifications of disability, including auditory and visual disability. We defined neurodevelopmental impairment as the presence of one or more of the following: non-ambulant cerebral palsy, developmental quotient greater than two standard deviations below the population mean, blindness (visual acuity $<6 / 60$ ), or deafness (any hearing impairment requiring or unimproved by amplification)

\section{Secondary outcomes}

- Duration of hospital admission

- Feeding intolerance that results in cessation of or reduction in enteral feeding

- Necrotising enterocolitis (NEC)

- Hyperglycaemia

- Diarrhoea
- Gastrointestinal disturbance

- Long-term measures of cardio-metabolic health such as insulin resistance, obesity, diabetes, and hypertension

\section{Search methods for identification of studies}

We used the criteria and standard methods of Cochrane and Cochrane Neonatal (see the Cochrane Neonatal search strategy for specialised register).

\section{Electronic searches}

We conducted a comprehensive search that included the Cochrane Central Register of Controlled Trials (CENTRAL; 2017, Issue 8) in the Cochrane Library; MEDLINE via PubMed (1966 to 21 February 2018); Embase (1980 to 21 February 2018); and the Cumulative Index to Nursing and Allied Health Literature (CINAHL; 1982 to 21 February 2018), using search terms related to carbohydrate supplementation of human milk, plus database-specific limiters for RCTs and neonates (see Appendix 1 for the full search strategies for each database). We did not apply language restrictions.

We searched clinical trials registries for ongoing and recently completed trials (clinicaltrials.gov; the World Health Organization International Trials Registry and Platform, and the International Standard Randomized Controlled Trials Number (ISRCTN) Registry).

\section{Searching other resources}

We searched the reference lists of articles included in this review to identify additional relevant articles. We did not search any additional conference proceedings.

\section{Data collection and analysis}

We used the guidelines and standardised methods of Cochrane and its Neonatal Review Group to assess the methodological quality of the included trial. Two review authors (EA and $\mathrm{JH})$ independently extracted data, compared data, and resolved differences. We used the standard method of Cochrane Neonatal to synthesise data and expressed results as relative risk and weighted mean difference.

\section{Selection of studies}

Review authors carried out the study selection process independently as follows: two review authors (EA and JB) independently screened the titles and abstracts of records identified by the searches. We resolved conflicts through discussion or by consultation with a third review author $(\mathrm{JH})$. We retrieved the full text of all potentially relevant articles and linked together reports of the same study. Two review authors (EA and JB) independently assessed full-text articles for inclusion or exclusion using the review eligibility criteria and resolved conflicts by discussion. We used Covidence during the study selection and data collection process.

\section{Data extraction and management}

We developed a data extraction form before gathering data to enable two review authors (EA and $\mathrm{JH}$ ) to independently extract information from study reports. We extracted data such as source details, study eligibility, study design, participant characteristics, intervention and control details, and outcomes. We resolved conflicts in the data extraction and management process by 
discussion. We then exported the data into Cochrane's statistical software, Review Manager 3 (RevMan 2014).

\section{Assessment of risk of bias in included studies}

Two review authors (EA and $\mathrm{JH}$ ) independently assessed the risk of bias (low, high, or unclear) of all included trials using the Cochrane 'Risk of bias' tool for the following domains (Higgins 2017).

- Sequence generation (selection bias).

- Allocation concealment (selection bias).

- Blinding of participants and personnel (performance bias).

- Blinding of outcome assessment (detection bias).

- Incomplete outcome data (attrition bias).

- Selective reporting (reporting bias).

- Any other bias.

We resolved disagreements by discussion. See Appendix 2 for a detailed description of risk of bias for each domain. We contacted the primary author of the included trial for confirmation that the two publications describe the same trial, and for clarification of study methods, specifically, methods related to randomisation and blinding during the trial.

\section{Measures of treatment effect}

We used the numbers of events in control and intervention groups of each study to calculate risk ratios (RRs) with 95\% confidence intervals (Cls) for dichotomous data. We planned to calculate mean differences (MDs) between treatment groups when outcomes were measured in the same way for continuous data. However, this was not possible because data for our pre-defined outcomes were scarce. Trial investigators measured duration of hospital stay using median and range values. We opted to report their findings narratively rather than convert values to mean and standard deviation because of the skewness of the data. We did not need to use standardised mean differences (SMDs) in this update as there was only one included trial. We reported $95 \% \mathrm{Cls}$ for all outcomes. We did not calculate number needed to treat for an additional beneficial outcome or number needed to treat for an additional harmful outcome because data were insufficient.

\section{Unit of analysis issues}

We did not identify any unit of analysis issues.

\section{Dealing with missing data}

We noted levels of attrition. We carried out analyses on an intention-to-treat basis, when possible, for all outcomes. We analysed all participants, when possible, in the treatment group to which they were randomised, regardless of the treatment received. We did not contact the primary author regarding missing data. We were unable to conduct sensitivity analyses and were unable to address the potential impact of missing data on findings of the review because data were insufficient.

\section{Assessment of heterogeneity}

We planned to assess whether the clinical and methodological characteristics of included studies were sufficiently similar for meta-analysis to provide a clinically meaningful summary. We planned to do this by assessing statistical heterogeneity using the $\mathrm{Chi}^{2}$ test and the $\mathrm{I}^{2}$ statistic. An $\mathrm{I}^{2}$ measurement greater than
$50 \%$ and a low $\mathrm{P}$ value $(<0.10)$ in the $\mathrm{Chi}^{2}$ test for heterogeneity were taken to indicate moderate to high heterogeneity. When we detected moderate to high heterogeneity, we planned to explore possible explanations through sensitivity and/or subgroup analyses. We planned to take statistical heterogeneity into account when interpreting trial results, especially if we noted any variation in the direction of effect. We were unable to perform any of these assessments, as we included only one trial.

\section{Assessment of reporting biases}

Some types of reporting bias (e.g. publication bias, multiple publication bias, language bias) reduce the likelihood that all studies eligible for a review will be retrieved. If all eligible studies are not retrieved, the review may be biased. We aimed to conduct a comprehensive search for eligible studies and were alert for duplication of data. We were unable to assess publication bias, as we found insufficient studies for any of the outcomes (10 or more trials required).

\section{Data synthesis}

We planned to use the GRADE approach, as outlined in the GRADE Handbook (Schünemann 2013), to assess the quality of evidence for the following clinically relevant outcomes: growth, neurodevelopment, duration of hospital admission, feeding intolerance that results in cessation or reduction in enteral feeding, and NEC. However, because of lack of data, we could assess quality using GRADE only for feeding intolerance and NEC.

Two review authors (EA and JB) independently assessed the quality of the evidence for each of the outcomes above. We considered evidence from RCTs as high quality but downgraded the evidence one level for serious (or two levels for very serious) limitations based upon the following: design (risk of bias), consistency across studies, directness of evidence, precision of estimates, and presence of publication bias. We used the GRADEpro GDT Guideline Development Tool to create a 'Summary of findings' table to report the quality of the evidence.

The GRADE approach yields an assessment of the quality of a body of evidence by one of four grades.

- High: we are very confident that the true effect lies close to that of the estimate of the effect.

- Moderate: we are moderately confident in the effect estimate: the true effect is likely to be close to the estimate of the effect, but there is a possibility that it is substantially different.

- Low: our confidence in the effect estimate is limited: the true effect may be substantially different from the estimate of the effect.

- Very low: we have very little confidence in the effect estimate: the true effect is likely to be substantially different from the estimate of effect.

\section{Subgroup analysis and investigation of heterogeneity}

We planned to perform subgroup and sensitivity analyses if we noted moderate to high heterogeneity. We planned to consider whether an overall summary was meaningful, and if it was, we planned to use a random-effects model to analyse it. We planned to carry out the following subgroup analyses to evaluate differences in outcomes: gestational age subgroups ( $<30$ vs 30 to $<34$ vs 34 to $<37$ completed weeks), birth weight subgroups ( $<1 \mathrm{~kg} v \mathrm{v} \geq 1 \mathrm{~kg}$ ), male 
versus female sex, and types of carbohydrate supplements (lactose vs other forms). However, data were insufficient for us to conduct any subgroup analyses.

\section{Sensitivity analysis}

We planned to conduct sensitivity analysis by examining only trials considered to have low risk of bias for allocation concealment and randomisation. We were unable to do this, as we included only one trial in this review.

\section{RES U L T S}

\section{Description of studies}

Please refer to the tables sections for study details (Included studies; Excluded studies).

\section{Results of the search}

Using search methods, we identified 548 records after duplicates had been removed. After trial and abstract screening, we excluded 545 records and retrieved three full-text articles for further analysis (Figure 1). We identified one trial (two publications) as eligible for inclusion in this review (Armanian 2014). 
Figure 1. Study flow diagram: review update

0 studies included in previous version of review

\section{9 records \\ identified through database searching (no limit -2018)}

50 additional records identified through other sources

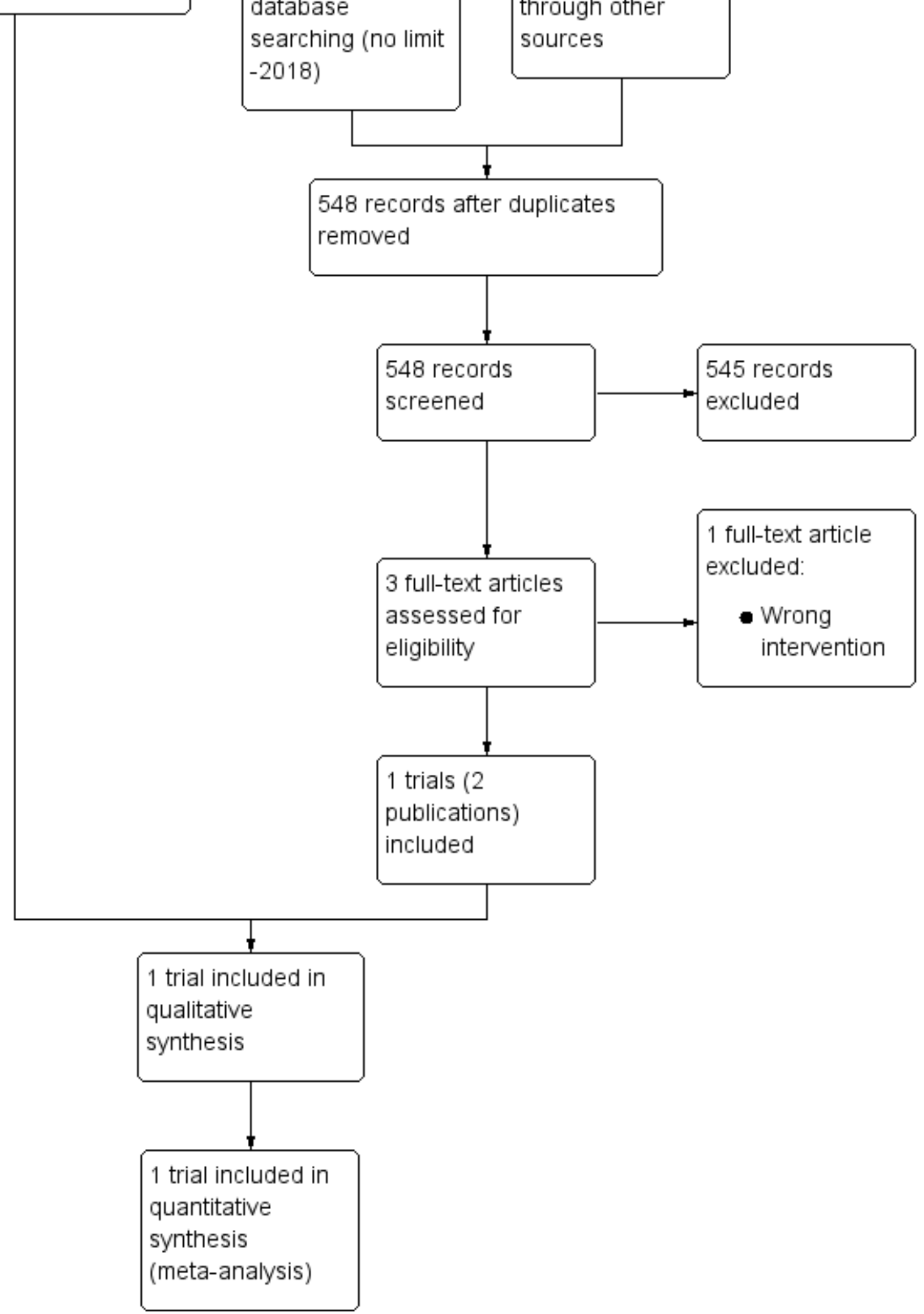




\section{Included studies}

One trial published in English met our inclusion criteria (Armanian 2014). This two-armed, single-centre study was carried out at a tertiary neonatal intensive care unit in Iran and included a total of 75 preterm infants. One publication stated that the trial was quasi-randomised and unblinded (Armanian 2014), but another publication by the same study authors stated that the study was randomised and blinded (Armanian 2016). It was conducted between December 2012 and November 2013 and reported on effects of prebiotic supplementation of human milk on preterm infants. We have summarised details of the included study in the Characteristics of included studies table.

\section{Participants}

Preterm infants involved in this trial were at $\leq 34$ gestational weeks with birth weight $\leq 1500$ grams. They had no asphyxia, major congenital anomalies, congenital cyanotic heart disease, gastrointestinal system anomalies, proven sepsis, or infection before the start of the study and were not transferred to other departments. Preterm infants in both intervention and control groups entered the study when their milk intake reached $30 \mathrm{~mL} / \mathrm{kg} /$ d.

\section{Interventions}

Researchers used a non-human short-chain galactooligosaccharides/long-chain fructo-oligosaccharides (GOS/ FOS) supplement in a 9:1 mixture. Trialists initially gave incremental doses of the supplement until the infant's milk intake reached 150 $\mathrm{mL} / \mathrm{kg} / \mathrm{d}$. However, it was not clear if these initial doses were given separately from breast milk. They then mixed a single dose of $1.5 \mathrm{~g} /$ $\mathrm{kg} / \mathrm{d}$ of supplement with breast milk and fed this to preterm infants in the intervention group for a day or two. We sought clarification from study authors on dosing and mode of administration of the intervention, but we have not yet received a response. Investigators fed only human milk to preterm infants in both intervention and control groups throughout the study. However, it is not clear if the milk was maternal or donor human milk or both.

\section{Comparators}

The control group received unsupplemented human milk.

\section{Outcomes}

The trial evaluated weight at day 30 but did not report our predefined outcome of weight gain in $\mathrm{g} / \mathrm{kg} / \mathrm{d}$. Study authors also reported duration of hospital stay, feeding intolerance, and NEC, sepsis, intraventricular haemorrhage, patent ductus arteriosus, time to full enteral feeds, and death. They provided no data on short- and long-term growth, body mass index, body composition, or neurodevelopmental and cardio-metabolic outcomes.

\section{Excluded studies}

We excluded one trial, for which the intervention was not relevant to our review, as it involved comparing a synbiotic versus no intervention (Nandhini 2016). We were unable to identify any ongoing trials involving carbohydrate supplementation of human milk in preterm infants. See Characteristics of excluded studies for details on exclusions.

\section{Risk of bias in included studies}

Please see Characteristics of included studies and the risk of bias graph and summary (Figure 2; Figure 3) for details.

Figure 2. Risk of bias graph: review authors' judgements about each risk of bias item presented as percentages across all included studies.

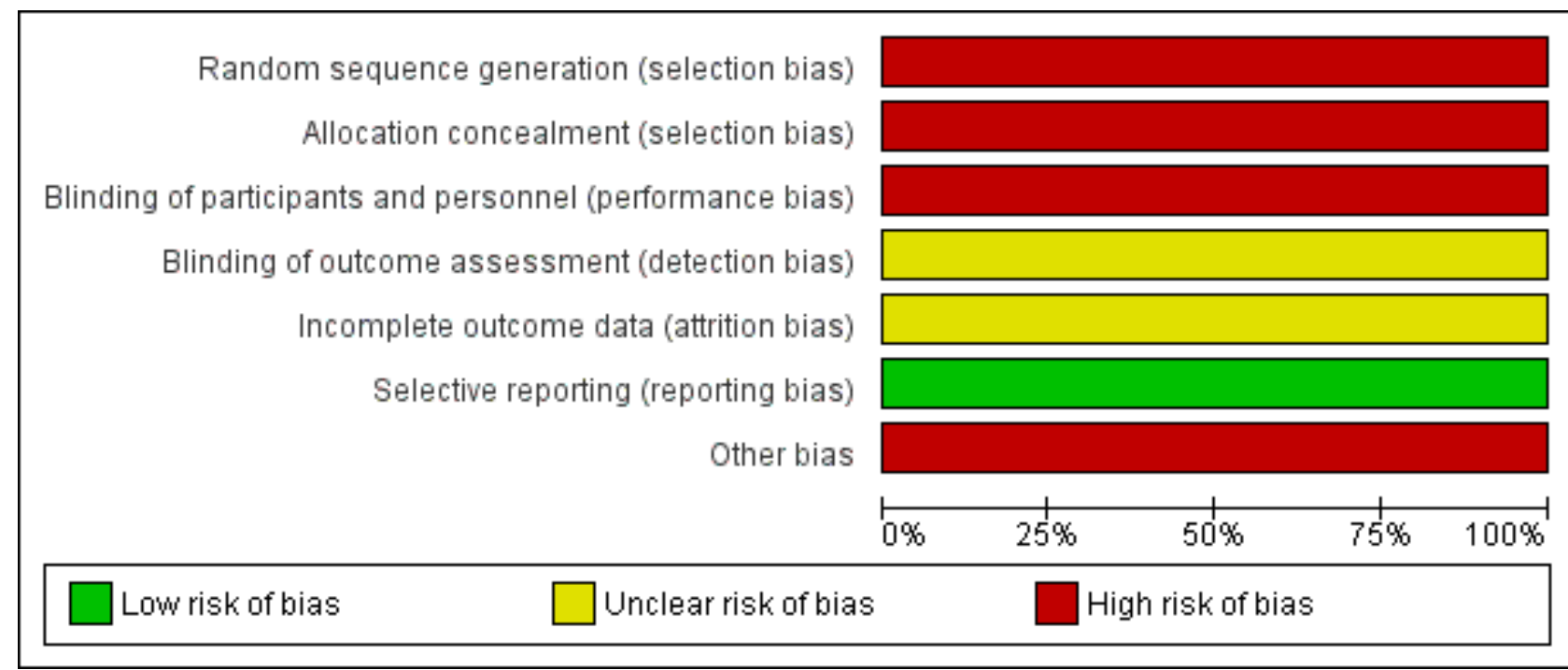


Figure 3. Risk of bias summary: review authors' judgements about each risk of bias item for each included study.

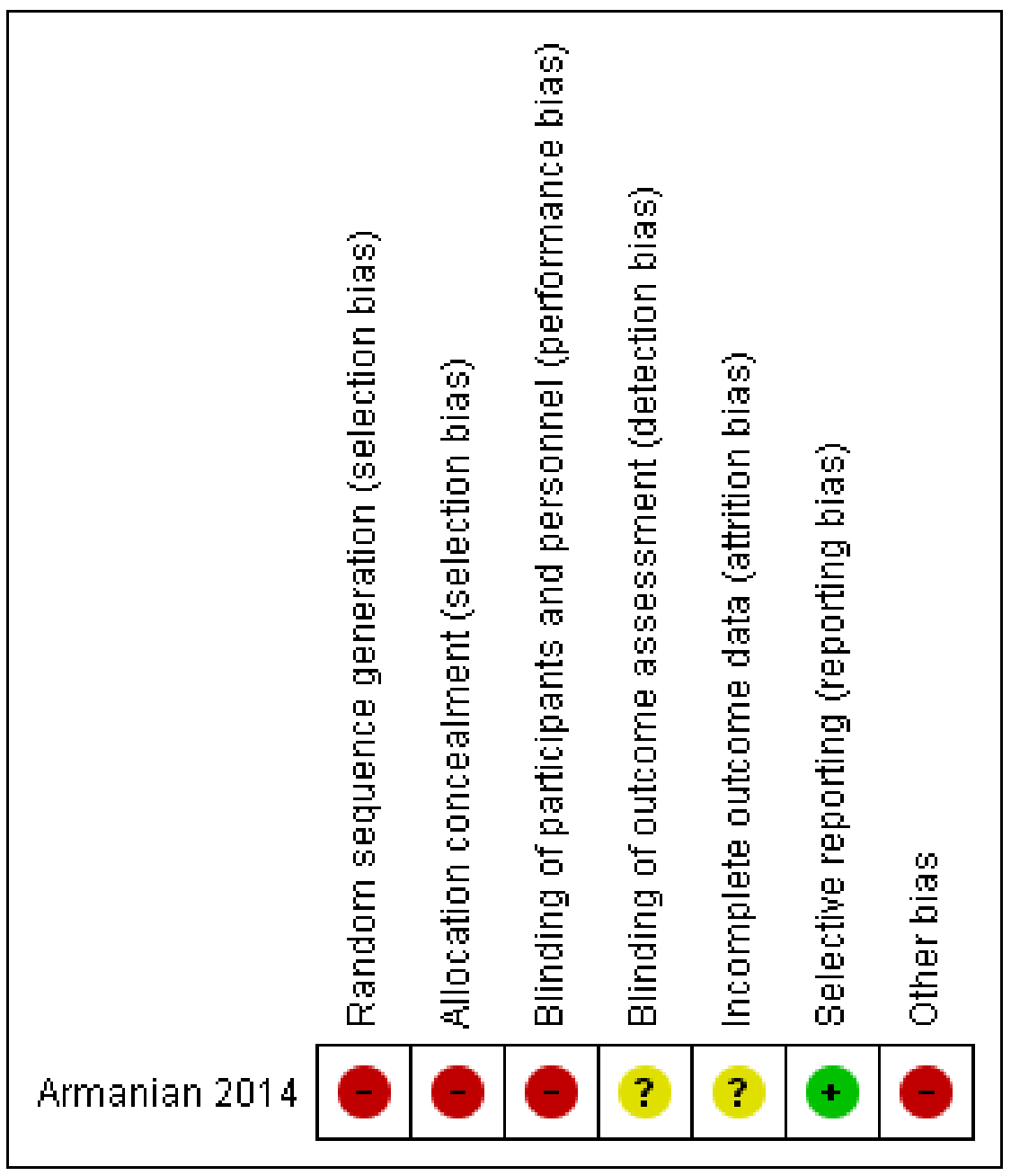

\section{Allocation}

Random sequence generation was performed through the use of odd or even file numbers; therefore we judged this as high risk. In addition, although unequal allocation of two controls to one case, as was done in this trial, may be scientifically desirable (Hey 2014), study authors did not report how this was done by using odd and even file numbers. We also judged allocation concealment as high risk because caregivers were not blinded and the allocation sequence was therefore easy to predict.

\section{Blinding}

This trial was not blinded, as study authors stated, "care providers were not blinded to an infant's protocol". We judged blinding of participants and personnel as high risk, as knowledge of the allocated intervention was not concealed from clinicians nor participants. We judged blinding of outcome assessors as unclear risk owing to insufficient methodological detail.

\section{Incomplete outcome data}

Study authors clearly reported reasons for withdrawals and dropouts and provided the missing numbers for each group. One reason given for missing numbers in each group was transfer to other departments. However, numbers transferred differed between groups, and study authors did not report why infants were transferred, as this potentially could be related to study outcomes. Study authors also reported no comparison of baseline characteristics between included and excluded participants. It is unclear whether researchers used an intention-to-treat approach, as they included four participants lost from both groups in the analysis and excluded the 13 randomised infants who were transferred. We judged attrition bias to be at unclear risk owing to insufficient methodological details.

\section{Selective reporting}

We viiewed no protocol. However, we included in the Results section all outcomes mentioned in the Methods section. We judged this to be of low risk.

\section{Other potential sources of bias}

We judged this as high risk owing to the publication of two reports for the same trial that reported different methods and different numbers of included infants. We were unable to reproduce the reported analyses from published data. 


\section{Effects of interventions}

See: Summary of findings for the main comparison Carbohydrate supplementation compared to control in preterm infants

\section{Carbohydrate supplementation versus control}

\subsection{Growth/Weight}

\subsubsection{Weight at day 30}

One randomised controlled trial including 75 infants contributed data (Armanian 2014). Prebiotic supplementation of human milk led to an increase in weight at day 30 compared with unsupplemented human milk (MD 160.4 grams, $95 \% \mathrm{Cl} 12.4$ to 308.4 grams; one RCT, N = 75 infants; very low-quality evidence). We downgraded the evidence for risk of bias, as methodological information provided was insufficient for judgement of the risk of bias, participants and events were few, and confidence intervals were wide.

\subsection{Feeding intolerance}

Armanian 2014 contributed data providing no clear evidence that prebiotic supplementation increased the risk of feeding intolerance (RR $0.64,95 \% \mathrm{Cl} 0.36$ to 1.15 ; one RCT, N = 75 infants; very lowquality evidence). We downgraded the evidence for risk of bias as methodological information was insufficient for judgement of risk of bias and participants and events were few.

\subsection{Necrotising enterocolitis}

One trial reported data on the incidence of necrotising enterocolitis (Armanian 2014), which showed no evidence of a clear difference in risk between prebiotic-supplemented and unsupplemented groups (RR $0.2,95 \% \mathrm{Cl} 0.02$ to 1.3 ; one RCT, $\mathrm{N}=75$ infants; very lowquality evidence). We downgraded the quality of evidence for risk of bias as methodological information was insufficient for judgement of risk of bias, participants and events were few, and confidence intervals were wide.

\subsection{Duration of hospital stay}

One trial reported on duration of hospital stay (Armanian 2014), noting that the prebiotic-supplemented group had a shorter hospital stay than the unsupplemented group. The median (range) length of hospital stay was 16 (9 to 45) days ( $95 \% \mathrm{Cl} 15.34$ to 24.09 ) and 25 ( 11 to 80 ) days ( $95 \% \mathrm{Cl} 25.52$ to 34.39 ), respectively. We downgraded the evidence for risk of bias to very low quality, as methodological information was insufficient for judgement of risk of bias, patients and events were few, and confidence intervals were wide.

Study authors also reported on sepsis, intraventricular haemorrhage (IVH), patent ductus arteriosus (PDA), time to full feeds, and death, which were not among our pre-defined outcomes. However, they provided no data for any of our other pre-specified primary or secondary outcomes, including long-term growth, body mass index, body composition, and neurodevelopmental and cardio-metabolic outcomes. We were unable to conduct our pre-specified subgroup analysis owing to insufficient data.

\section{DISCUSSION}

\section{Summary of main results}

We identified one trial for inclusion in this review (Armanian 2014). In this trial, the prebiotic-supplemented group showed an increase in mean weight at 30 days of age and shorter length of hospital stay compared to the control group. Study authors provided no evidence of a clear difference in risk of feeding intolerance and necrotising enterocolitis (NEC) between intervention and control groups. Except for weight at day 30, no data were available for assessment of effects of carbohydrate supplementation on shortand long-term growth, body mass index (BMI), body composition, and neurodevelopmental and cardio-metabolic outcomes.

\section{Overall completeness and applicability of evidence}

The only trial included in this review is limited in applicability because it was conducted among a small sample of preterm infants in Iran. However, the outcomes assessed are common to all preterm infants. This trial shows that prebiotic carbohydrate supplementation of human milk may be feasible in developing countries.

\section{Quality of the evidence}

The included trial had high risk of selection and performance bias owing to quasi-randomisation and lack of blinding of caregivers. In addition, two reports of this trial were inconsistent regarding methods and numbers of included infants, and we were unable to reproduce analyses of findings for NEC and weight at day 30 , as reported in the publication. The overall quality of evidence for outcomes assessed according to GRADE was very low owing to insufficient methodological details, high risk of bias, small sample size, few events, and variable precision.

\section{Potential biases in the review process}

The comprehensive search strategy, use of appropriate search terminology, and lack of language restriction in this review minimised bias and increased the likelihood of identifying all relevant articles. Additionally, involvement of multiple authors in the review process to independently screen records for inclusion and extract data for analysis limited the introduction of bias into the review. However, there is always potential for publication bias. Unfortunately, we were unable to create funnel plots and evaluate this potential risk because we included only one trial in the review.

\section{Agreements and disagreements with other studies or reviews}

To the best of our knowledge, this is the only systematic review covering this topic, and our previous review found no trials eligible for inclusion.

\section{AUTHORS' CONCLUSIONS}

\section{Implications for practice}

The only included trial shows very low-quality evidence of the effects of prebiotic carbohydrate supplementation of human milk in preterm infants, and provided no data on the short- and long-term health benefits and harms of digestible carbohydrate supplementation of human milk in this population. Therefore, we 
are unable to make any clinical suggestions on the basis of the single included trial.

\section{Implications for research}

Currently, we have found little evidence to support or refute the practice of carbohydrate supplementation of human milk in preterm infants. If further trials seek to examine prebiotic or digestible carbohydrate supplementation done as a component of multi-nutrient fortification, trialists should assess the optimum concentrations of carbohydrate supplements, adverse effects, and short- and long-term growth and health benefits for preterm infants.

\section{A C K N OWLEDGEMENTS}

Emma Amissah was supported by a doctoral scholarship from the University of Auckland.

Julie Brown was supported by a grant from the Health Research Council of New Zealand.

We acknowledge the support of Caroline A Crowther in preparing this review, and the work of Carl A Kuschel as lead author of the original review (Kuschel 2000). 


\section{R E F E R E N C E S}

\section{References to studies included in this review}

Armanian 2014 \{published data only\}

* Armanian AM, Sadeghina A, Hoseinzadeh M, Mirlohi M, Feizi A, Salehimehr N, et al. The effect of neutral oligosaccharides on reducing the incidence of necrotizing enterocolitis in preterm infants: a randomized clinical trial. International Journal of Preventive Medicine 2014;5(11):1387-95. [PUBMED: 25538834]

Armanian AM, Sadeghnia A, Hoseinzadeh M, Mirlohi M, Feizi A, Salehimehr N, et al. The effect of neutral oligosaccharides on fecal microbiota in premature infants fed exclusively with breast milk: a randomized clinical trial. Journal of Research in Pharmacy Practice 2016;5(1):27-34. [DOI: 10.4103/2279-042X.176558; PUBMED: 26985433]

\section{References to studies excluded from this review}

Nandhini 2016 \{published data only\}

Nandhini LP, Biswal N, Adhisivam B, Mandal J, Bhat BV, Mathai B. Synbiotics for decreasing incidence of necrotizing enterocolitis among preterm neonates - a randomized controlled trial. Journal of Maternal-Fetal \& Neonatal Medicine 2016;29(5):821-5. [DOI: 10.3109/14767058.2015.1019854; PUBMED: 25754214]

\section{Additional references}

\section{Armanian 2016}

Armanian AM, Sadeghnia A, Hoseinzadeh M, Mirlohi M, Feizi A, Salehimehr N, et al. The effect of neutral oligosaccharides on fecal microbiota in premature infants fed exclusively with breast milk: a randomized clinical trial. Journal of Research in Pharmacy Practice 2016;5(1):27-34. [DOI: 10.4103/2279-042X.176558; PUBMED: 26985433]

\section{Ayede 2011}

Ayede Al. Achieving optimal feeds for preterm babies, recommendations and realities in practice: Nigerian perspective. Annals of Ibadan Postgraduate Medicine 2011;9(1):1-7. [PUBMED: 25161480]

\section{Ballard 2013}

Ballard O, Morrow AL. Human milk composition: nutrients and bioactive factors. Pediatric Clinics of North America 2013;60(1):49-74. [DOI: 10.1016/j.pcl.2012.10.002; PUBMED: 23178060]

\section{Belfort 2016}

Belfort MB, Anderson PJ, Nowak VA, Lee KJ, Molesworth C, Thompson DK, et al. Breast milk feeding, brain development, and neurocognitive outcomes: a 7-year longitudinal study in infants born at less than 30 weeks' gestation. Journal of Pediatrics 2016;177:133-9.e1. [DOI: 10.1016/j.jpeds.2016.06.045; PUBMED: 27480198]

\section{Blackburn 2017}

Blackburn S. Maternal, Fetal, \& Neonatal Physiology - E-book: A Clinical Perspective. St. Louis, Missouri: Elsevier Health Sciences, 2017.

\section{Blank 2012}

Blank D, Dotz V, Geyer R, Kunz C. Human milk oligosaccharides and Lewis blood group: individual high-throughput sample profiling to enhance conclusions from functional studies. Advances in Nutrition 2012;3(3):440S-9S. [DOI: 10.3945/ an.111.001446; PUBMED: 22585923]

\section{Bode 2012}

Bode L. Human milk oligosaccharides: every baby needs a sugar mama. Glycobiology 2012;22(9):1147-62. [DOI: 10.1093/glycob/ cws074; PUBMED: 22513036]

\section{Brown 2014}

Brown LD, Masor ML, Hay WW. High-protein formulas: evidence for use in preterm infants. Clinics in Perinatology 2014;41(2):383-403. [DOI: 10.1016/j.clp.2014.02.002; PUBMED: 24873839]

\section{Brown 2016}

Brown JV, Embleton ND, Harding JE, McGuire W. Multinutrient fortification of human milk for preterm infants. Cochrane Database of Systematic Reviews 2016, Issue 5. [DOI: 10.1002/14651858.CD000343.pub3]

\section{Cowett 2012}

Cowett RM. Principles of Perinatal-Neonatal Metabolism. 2nd Edition. New York: Springer Science \& Business Media, 2012 (reprint of 1998 edition).

\section{Duggan 2008}

Duggan C, Watkins JB, Walker WA. Nutrition in Pediatrics: Basic Science, Clinical Applications. Hamilton, Ontario: BC Decker Inc, 2008.

\section{Duijts 2010}

Duijts L, Jaddoe VWV, Hofman A, Moll HA. Prolonged and exclusive breastfeeding reduces the risk of infectious diseases in infancy. Pediatrics 2010;126(1):e18-25. [DOI: 10.1542/ peds.2008-3256; PUBMED: 20566605]

\section{Elzouki 2012}

Elzouki AY, Harfi HA, Nazer H, Stapleton FB, Oh W, Whitley RJ (editors). Textbook of Clinical Pediatrics. 2nd Edition. New York: Springer Science \& Business Media, 2012.

\section{Erasmus 2002}

Erasmus HD, Ludwig-Auser HM, Paterson PG, Sun D, Sankaran K. Enhanced weight gain in preterm infants receiving lactasetreated feeds: a randomized, double-blind, controlled trial. Journal of Pediatrics 2002;141(4):532-7. [DOI: 10.1067/ mpd.2002.127499; PUBMED: 12378193] 


\section{Fanaroff 2012}

Fanaroff JM, Fanaroff AA. Klaus and Fanaroff's Care of the HighRisk Neonate E-Book. 6th Edition. St. Louis, Missouri: Elsevier Health Sciences, 2012.

\section{Fenton 2013}

Fenton TR, Nasser R, Eliasziw M, Kim JH, Bilan D, Sauve R. Validating the weight gain of preterm infants between the reference growth curve of the fetus and the term infant. $B M C$ Pediatrics 2013;13:92. [DOI: 10.1186/1471-2431-13-92; PUBMED: 23758808]

\section{Gabrielli 2011}

Gabrielli O, Zampini L, Galeazzi T, Padella L, Santoro L, Peila C, et al. Preterm milk oligosaccharides during the first month of lactation. Pediatrics 2011;128(6):e1520-31. [DOI: 10.1542/ peds.2011-1206; PUBMED: 22123889]

\section{GRADEpro GDT [Computer program]}

GRADE Working Group, McMaster University. GRADEpro GDT. Version accessed 01 September 2017. Hamilton (ON): GRADE Working Group, McMaster University, 2014.

\section{Gregory 2005}

Gregory K. Update on nutrition for preterm and full-term infants. Journal of Obstetric, Gynecologic, and Neonatal Nursing 2005;34(1):98-108. [DOI: 10.1177/0884217504272805; PUBMED: 15673653]

\section{Hay 2008}

Hay WW Jr. Strategies for feeding the preterm infant. Neonatology 2008;94(4):245-54. [DOI: 10.1159/000151643; PUBMED: 18836284]

\section{Hay 2017}

Hay WW Jr, Hendrickson KC. Preterm formula use in the preterm very low birth weight infant. Seminars in Fetal \& Neonatal Medicine 2017;22(1):15-22. [DOI: 10.1016/j.siny.2016.08.005; PUBMED: 27595621]

\section{Heine 2017}

Heine RG, AlRefaee F, Bachina P, De Leon JC, Geng L, Gong S, et al. Lactose intolerance and gastrointestinal cow's milk allergy in infants and children - common misconceptions revisited. World Allergy Organization Journal 2017;10(1):41. [DOI: 10.1186/ s40413-017-0173-0; PUBMED: 29270244]

\section{Hey 2014}

Hey SP, Kimmelman J. The questionable use of unequal allocation in confirmatory trials. Neurology 2014;82(1):77-9. [DOI: 10.1212/01.wnl.0000438226.10353.1c; PUBMED: 24306005]

\section{Higgins 2017}

Higgins JP, Green S (editors). Cochrane Handbook for Systematic Reviews of Interventions Version 5.2.0 (updated June 2017). The Cochrane Collaboration, 2017. Available from https://training.cochrane.org/handbook.

\section{Jantscher-Krenn 2012}

Jantscher-Krenn E, Bode L. Human milk oligosaccharides and their potential benefits for the breast-fed neonate. Minerva Pediatrica 2012;64(1):83-99. [PUBMED: 22350049]

\section{Klein 2002}

Klein CJ. Nutrient requirements for preterm infant formulas. Journal of Nutrition 2002;132(6 Suppl 1):1395S-577S. [DOI: 10.1093/jn/132.6.1395S; PUBMED: 12042465]

\section{Kuschel 2000}

Kuschel CA, Harding JE. Carbohydrate supplementation of human milk to promote growth in preterm infants. Cochrane Database of Systematic Reviews 2000, Issue 2. [DOI: 10.1002/14651858.CD000280]

\section{Mahajan 2017}

Mahajan S, Chawla D, Kaur J, Jain S. Macronutrients in breast milk of mothers of preterm infants. Indian Pediatrics 2017;54(8):635-7. [PUBMED: 28607212]

\section{Mangili 2017}

Mangili G, Garzoli E. Feeding of preterm infants and fortification of breast milk. Pediatria Medica e Chirurgica [Medical and Surgical Pediatrics] 2017;39(2):62-6. [DOI: 10.4081/ pmc.2017.158; PUBMED: 28673079]

\section{Martin 2016}

Martin CR, Ling PR, Blackburn GL. Review of infant feeding: key features of breast milk and infant formula. Nutrients 2016;8(5):E279. [DOI: 10.3390/nu8050279; 27187450]

\section{Morrow 2011}

Morrow AL, Meinzen-Derr J, Huang P, Schibler KR, Cahill T, Keddache $\mathrm{M}$, et al. Fucosyltransferase 2 non-secretor and low secretor status predicts severe outcomes in premature infants. Journal of Pediatrics 2011;158(5):745-51. [DOI: 10.1016/ j.jpeds.2010.10.043; PUBMED: 21256510]

\section{RevMan 2014 [Computer program]}

Nordic Cochrane Centre, The Cochrane Collaboration. Review Manager 5 (RevMan 5). Version 5.3. Copenhagen: Nordic Cochrane Centre, The Cochrane Collaboration, 2014.

\section{Schünemann 2013}

Schünemann H, Brożek J, Guyatt G, Oxman A, editor(s). Handbook for Grading the Quality of Evidence and the Strength of Recommendations Using the GRADE Approach (updated October 2013). GRADE Working Group, 2013. Available from gdt.guidelinedevelopment.org/app/handbook/handbook.html.

\section{Sullivan 2010}

Sullivan S, Schanler RJ, Kim JH, Patel AL, Trawöger R, KiechlKohlendorfer $U$, et al. An exclusively human milk-based diet Is associated with a lower rate of necrotizing enterocolitis than a diet of human milk and bovine milk-based products. Journal of Pediatrics 2010;156(4):562-7. [DOI: 10.1016/j.jpeds.2009.10.040; PUBMED: 20036378] 
Velaphi 2011

Velaphi S. Nutritional requirements and parenteral nutrition in preterm infants. South African Journal of Clinical Nutrition 2011;24(3):S27-31.

\section{Vohr 2006}

Vohr BR, Poindexter BB, Dusick AM, McKinley LT, Wright LL, Langer JC, et al. NICHD Neonatal Research Network. Beneficial effects of breast milk in the neonatal intensive care unit on the developmental outcome of extremely low birth weight infants at 18 months of age. Pediatrics 2006;118(1):e115-123. [DOI: 10.1542/peds.2005-2382; PUBMED: 16818526]

\section{CHARACTERISTICS OF STUDIES}

\section{Characteristics of included studies [ordered by study ID]}

\section{References to other published versions of this review Kuschel 1999}

Kuschel CA, Harding JE. Carbohydrate supplementation of human milk to promote growth in preterm infants. Cochrane Database of Systematic Reviews 1999, Issue 2. [DOI: 10.1002/14651858.CD000280]

* Indicates the major publication for the study

Armanian 2014

\begin{tabular}{ll} 
Methods & Quasi-randomized controlled trial, single centre \\
\hline Participants & Inclusion criteria: infants with birth weight $\leq 1500$ grams, gestational age $\leq 34$ weeks, who had no for- \\
mula feeds. Infants were included when their milk feeding volume reached $30 \mathrm{~mL} / \mathrm{kg} / \mathrm{d}$. \\
Exclusion criteria: infants with asphyxia, major congenital anomalies, congenital cyanotic heart dis- \\
ease, gastrointestinal system anomalies, proven sepsis, or infection immediately before the start of the \\
study, transferred to other departments, refused to participate \\
Setting: NICUs of the Isfahan University of Medical Sciences (Alzahra and Shahid Beheshti Hospital) \\
Timing: December 2012 to November 2013
\end{tabular}

Interventions

Breast milk supplemented with 9:1 mixture of short-chain galacto-oligosaccharide/long-chain fructo-oligosaccharide $(n=25)$ vs unsupplemented breast milk $(n=50)$

Not clear when the intervention ceased

Outcomes

Primary outcomes: incidence of suspected NEC

Secondary outcomes: milk volumes, feeding intolerance (presence of milk in the stomach 2 hours after a meal, i.e. gastric residue), abdominal distension, postnatal age when full enteral feeding was attained, death, length of hospital stay, weight at day 30 , associated patent ductus arteriosus, and intraventricular haemorrhage

Notes

Conflicts of interest: none declared, but Nutricia MMP, Mashad, Iran is acknowledged.

Source of support: This paper is derived from a residency thesis (No. 392237) at Isfahan University of Medical Sciences. No details of source of funding are provided.

Study authors published 2 reports of the same trial but reported different methods regarding blinding and randomisation, and included different numbers of infants. The first publication reported quasi-randomisation and lack of blinding of caregivers, and the second publication reported computer-generated randomisation and blinding of the investigator and nurse. Study authors confirmed via email that publications described the same trial, but they have not yet clarified the different methods reported. We chose to include details from the first publication, as it involved a larger sample size and assessed outcomes relevant to this review.

\section{Risk of bias}

\begin{tabular}{lll} 
Bias & Authors' judgement & Support for judgement \\
\hline $\begin{array}{l}\text { Random sequence genera- } \\
\text { tion (selection bias) }\end{array}$ & High risk & $\begin{array}{l}\text { Infants were randomised based on files ending in odd or even numbers. It is } \\
\text { not clear how the 2:1 allocation was achieved. }\end{array}$ \\
\hline
\end{tabular}


Armanian 2014 (Continued)

Allocation concealment High risk Randomisation was done by an independent employee, but allocation was not (selection bias) blinded and could be predicted.

Blinding of participants High risk and personnel (performance bias)

All outcomes
Study authors stated, "care providers were not blinded to an infant's protocol".

\section{Blinding of outcome as- Unclear risk sessment (detection bias)} All outcomes
Suspected NEC diagnosis was clinical and therefore was potentially subject to bias. However, it is unclear whether outcome assessors were among the care providers who were not blinded.
Incomplete outcome data Unclear risk (attrition bias)

All outcomes

Losses to follow-up were disclosed as follows: of 131 eligible infants, 24 were excluded for having major congenital anomalies, gastrointestinal system anomalies, asphyxia, or sepsis, and parents of 19 infants refused to participate or were transferred to other wards. Of 88 infants randomised, 13 ( 9 in the prebiotic group and 4 in the control group) were transferred to other departments. The 13 excluded after randomisation appear to be attributable to reasonable attrition. However, the reasons for transfer, which could be related to outcomes assessed, were not stated. It also was not clear whether study authors compared baseline characteristics between participants included and excluded from the study. One loss to follow-up and 1 death occurred in each group, but these appear to be included in the analysis, although the 13 transferred to other departments were excluded, making it difficult to determine whether an intention-to-treat approach was used.

\begin{tabular}{lll}
\hline $\begin{array}{l}\text { Selective reporting (re- } \\
\text { porting bias) }\end{array}$ & Low risk & $\begin{array}{l}\text { The study protocol was not available, but researchers reported results for all } \\
\text { outcomes listed in the methods. }\end{array}$ \\
\hline Other bias & High risk & $\begin{array}{l}\text { Study authors published } 2 \text { reports of the same trial that described different } \\
\text { methods and different numbers of included infants. We were unable to repro- } \\
\text { duce their analyses from the published data. }\end{array}$ \\
\hline
\end{tabular}

NEC: necrotising enterocolitis.

NICU: neonatal intensive care unit.

Characteristics of excluded studies [ordered by study ID]

\begin{tabular}{ll}
\hline Study & Reason for exclusion \\
\hline Nandhini 2016 & Wrong intervention - synbiotic vs no intervention
\end{tabular}

\section{DATA AND ANALYSES}

\section{Comparison 1. Carbohydrate supplementation versus control}

\begin{tabular}{lllll}
\hline Outcome or subgroup title & $\begin{array}{l}\text { No. of } \\
\text { studies }\end{array}$ & $\begin{array}{l}\text { No. of } \\
\text { partici- } \\
\text { pants }\end{array}$ & Statistical method & Effect size \\
\hline 1 Growth/Weight & 1 & & Mean Difference (IV, Fixed, 95\% CI) & Subtotals only \\
\hline
\end{tabular}




\begin{tabular}{llllll}
\hline Outcome or subgroup title & $\begin{array}{l}\text { No. of } \\
\text { studies }\end{array}$ & $\begin{array}{l}\text { No. of } \\
\text { partici- } \\
\text { pants }\end{array}$ & Statistical method & Effect size \\
\hline 1.1 Weight at day $30(\mathrm{~g})$ & 1 & 75 & Mean Difference (IV, Fixed, 95\% Cl) & $160.40[12.41,308.39]$ \\
\hline 2 Feeding intolerance & 1 & 75 & Risk Ratio (M-H, Fixed, 95\% Cl) & $0.64[0.36,1.15]$ \\
\hline 3 Necrotising enterocolitis & 1 & 75 & Risk Ratio (M-H, Fixed, 95\% Cl) & $0.18[0.02,1.33]$ \\
\hline
\end{tabular}

Analysis 1.1. Comparison 1 Carbohydrate supplementation versus control, Outcome 1 Growth/Weight.

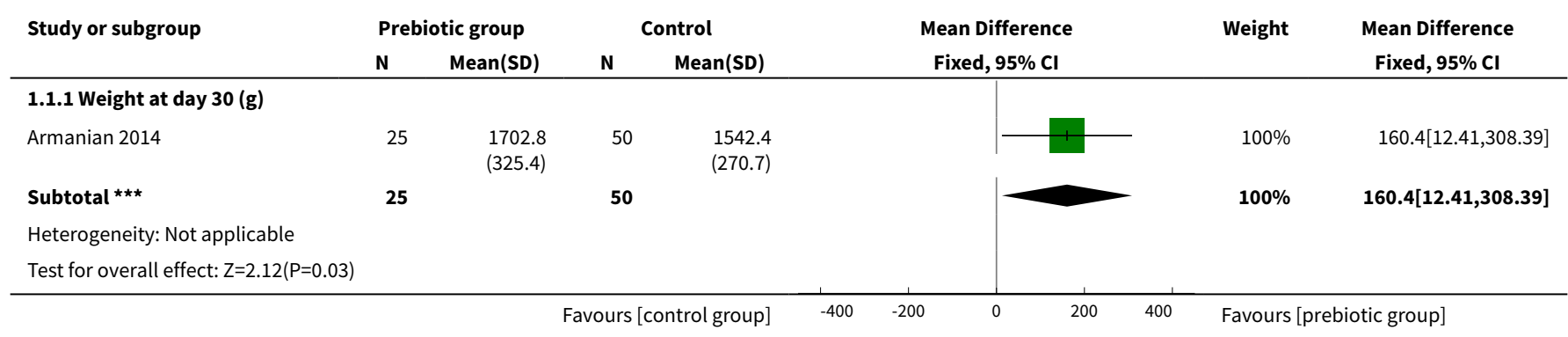

\section{Analysis 1.2. Comparison 1 Carbohydrate supplementation versus control, Outcome 2 Feeding intolerance.}

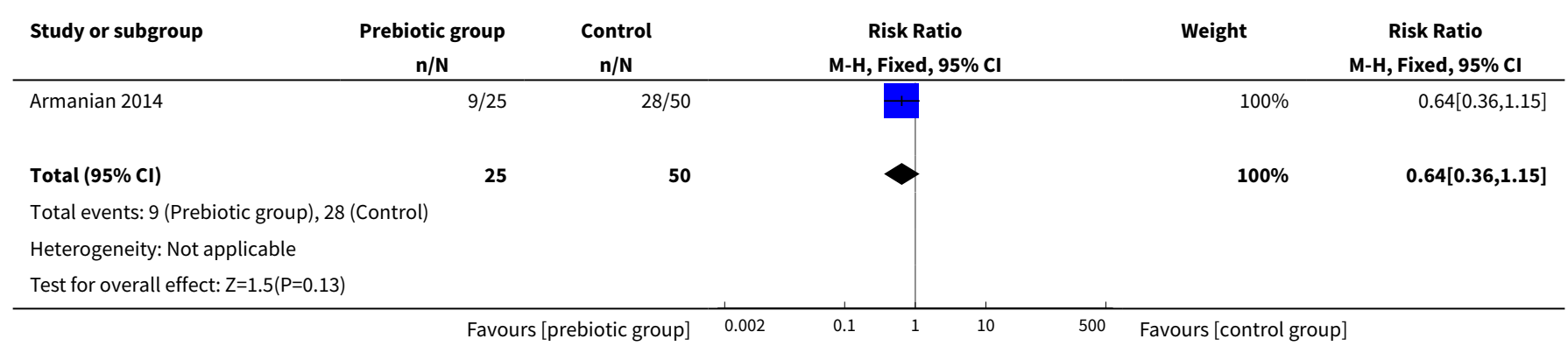

Analysis 1.3. Comparison 1 Carbohydrate supplementation versus control, Outcome 3 Necrotising enterocolitis.

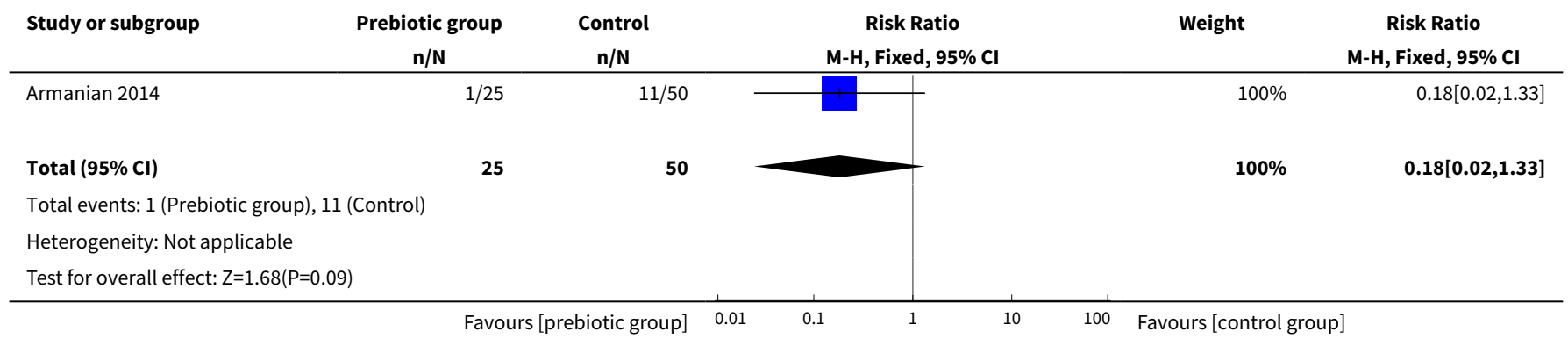




\section{AP PE N D I C E S}

\section{Appendix 1. Standard search methods}

PubMed:

(((Dietary Carbohydrates[Mesh] OR Carbohydrate*[tiab] OR Glucans[Mesh] OR Sucrose[Mesh] OR glucan*[tiab] OR monosaccharide*[tiab] OR disaccharide* [tiab] OR oligosaccharide*[tiab] OR polysaccharide*[tiab] OR polycose[tiab] OR lactose[tiab] OR sucrose[tiab] OR corn syrup[tiab)) AND (((Milk, Human[MeSH] OR breastmilk* [tiab])) OR (((human[tiab] OR breast[tiab] OR expressed[tiab] OR mother[tiab] OR maternal[tiab] OR donor*[tiab])) AND milk*[tiab]))) AND (((infant, newborn[MeSH] OR newborn OR neonate OR neonatal OR premature OR low birth weight OR VLBW OR LBW or infan* or neonat*) AND (randomized controlled trial [pt] OR controlled clinical trial [pt] OR randomized [tiab] OR placebo [tiab] OR drug therapy [sh] OR randomly [tiab] OR trial [tiab] OR groups [tiab]) NOT (animals [mh] NOT humans [mh])))

Embase:

\begin{tabular}{|c|c|}
\hline 1 & exp carbohydrate diet/ \\
\hline 2 & exp glucan/ \\
\hline 3 & exp sucrose/ \\
\hline 4 & $\begin{array}{l}\text { (Carbohydrate* or glucan }{ }^{\star} \text { or monosaccharide }{ }^{\star} \text { or disaccharide }{ }^{\star} \text { or oligosaccharide }{ }^{\star} \text { or polysac- } \\
\text { charide }^{\star} \text { or polycose or lactose or sucrose or corn syrup).ti,ab. }\end{array}$ \\
\hline 5 & 1 or 2 or 3 or 4 \\
\hline 6 & exp breast milk/ \\
\hline 7 & ((human or breast or expressed) adj milk\$).ti,ab. \\
\hline 8 & ((mother\$ or maternal or donor\$) adj milk\$).ti,ab. \\
\hline 9 & 6 or 7 or 8 \\
\hline 10 & $\begin{array}{l}\text { (infan* or newborn or neonat* or premature or very low birth weight or low birth weight or VLBW or } \\
\text { LBW).mp. }\end{array}$ \\
\hline 11 & exp infant/ \\
\hline 12 & 10 or 11 \\
\hline 13 & (human not animal).mp. \\
\hline 14 & $\begin{array}{l}\text { (randomized controlled trial or controlled clinical trial or randomized or placebo or clinical trials as } \\
\text { topic or randomly or trial or clinical trial).mp. }\end{array}$ \\
\hline 15 & 12 and 13 and 14 \\
\hline 16 & 5 and 9 and 15 \\
\hline
\end{tabular}

CINAHL: 


\begin{tabular}{ll}
\hline S1 & (MH "Dietary Carbohydrates+") \\
\hline S2 & (MH "Glucans+") \\
\hline S3 & (MH "Sucrose+") \\
\hline S4 & $\begin{array}{l}\text { Carbohydrate* OR glucan* OR monosaccharide* OR disaccharide* OR oligosaccharide* OR poly- } \\
\text { saccharide* OR polycose OR lactose OR sucrose OR corn syrup }\end{array}$ \\
\hline S5 & S1 OR S2 OR S3 OR S4 \\
\hline S6 & ( human OR breast OR expressed OR mother* OR maternal OR donor* ) AND milk* \\
\hline S7 & breastmilk* \\
\hline S8 & $\begin{array}{l}\text { S6 OR S7 } \\
\text { S9 }\end{array}$ \\
\hline S10 & $\begin{array}{l}\text { (infan }{ }^{\star} \text { OR newborn OR neonat }{ }^{\star} \text { OR premature OR low birth weight OR VLBW OR LBW) AND (ran- } \\
\text { S5 AND S8 AND S9 }\end{array}$ \\
\hline
\end{tabular}

Cochrane Library:

\begin{tabular}{|c|c|}
\hline 1 & MESH DESCRIPTOR Dietary Carbohydrates EXPLODE ALL AND CENTRAL:TARGET \\
\hline 2 & MESH DESCRIPTOR Sucrose EXPLODE ALL AND CENTRAL:TARGET \\
\hline 3 & MESH DESCRIPTOR Glucans EXPLODE ALL AND CENTRAL:TARGET \\
\hline 4 & $\begin{array}{l}\text { (Carbohydrate } \text { or glucan }^{\star} \text { or monosaccharide* or disaccharide* } \text { or oligosaccharide* or polysac- } \\
\text { charide }^{\star} \text { or polycose or lactose or sucrose or corn syrup):TI,AB,KW AND CENTRAL:TARGET }\end{array}$ \\
\hline 5 & \#1 OR \#2 OR \#3 OR \#4 \\
\hline 6 & MESH DESCRIPTOR Milk, Human EXPLODE ALL AND CENTRAL:TARGET \\
\hline 7 & ((human OR breast OR expressed) NEAR2 milk):TI,AB,KW AND CENTRAL:TARGET \\
\hline 8 & ((mother ${ }^{\star}$ or maternal or donor $\left.{ }^{\star}\right)$ NEAR2 milk $\left.{ }^{\star}\right):$ TI,AB,KW AND CENTRAL:TARGET \\
\hline 9 & \#6 OR \#7 OR \#8 AND CENTRAL:TARGET \\
\hline 10 & $\begin{array}{l}\text { (infan* or newborn or neonat }{ }^{\star} \text { or premature or preterm or very low birth weight or low birth weight } \\
\text { or VLBW or LBW) AND CENTRAL:TARGET }\end{array}$ \\
\hline 11 & \#5 AND \#9 AND \#10 \\
\hline
\end{tabular}




\section{Appendix 2. Risk of bias tool}

We used the standard methods of Cochrane and Cochrane Neonatal to assess the methodological quality (to meet the validity criteria) of trials. For the included trial, we sought information from trial investigators regarding the intervention, the method of randomisation, and blinding, but to date we have received no response. We assessed each criterion as low, high, or unclear risk. Two review authors separately assessed the study. We resolved any disagreement by discussion. We added this information to the table 'Characteristics of included studies'. We evaluated the following issues and entered the findings into the risk of bias table.

\section{Sequence generation (checking for possible selection bias). Was the allocation sequence adequately generated?}

For the included study, we categorised the method used to generate the allocation sequence as:

- low risk (any truly random process, e.g. random number table; computer random number generator);

- high risk (any non-random process, e.g. odd or even date of birth; hospital or clinic record number); or

- unclear risk.

\section{Allocation concealment (checking for possible selection bias). Was allocation adequately concealed?}

For the included study, we categorised the method used to conceal the allocation sequence as:

- low risk (e.g. telephone or central randomisation; consecutively numbered sealed opaque envelopes);

- high risk (e.g. open random allocation; unsealed or non-opaque envelopes, alternation; date of birth); or

- unclear risk.

3. Blinding of participants and personnel (checking for possible performance bias). Was knowledge of the allocated intervention adequately prevented during the study?

For the included study, we categorised the methods used to blind study participants and personnel from knowledge of which intervention a participant received. Blinding was assessed separately for different outcomes or classes of outcomes. We categorised the methods as:

- low risk, high risk, or unclear risk for participants; and

- low risk, high risk, or unclear risk for personnel.

4. Blinding of outcome assessment (checking for possible detection bias). Was knowledge of the allocated intervention adequately prevented at the time of outcome assessment?

For the included study, we categorised the methods used to blind outcome assessment. Blinding was assessed separately for different outcomes or classes of outcomes. We categorised the methods as:

- low risk for outcome assessors;

- high risk for outcome assessors; or

- unclear risk for outcome assessors.

5. Incomplete outcome data (checking for possible attrition bias through withdrawals, dropouts, protocol deviations). Were incomplete outcome data adequately addressed?

For the included study and for each outcome, we described the completeness of data including attrition and exclusions from the analysis. We noted whether attrition and exclusions were reported, numbers included in the analysis at each stage (compared with the total randomised participants), reasons for attrition or exclusion when reported, and whether missing data were balanced across groups or were related to outcomes. When sufficient information was reported or supplied by the trial authors, we re-included missing data in the analyses. We categorised the methods as:

- low risk (<20\% missing data);

- high risk ( $\geq 20 \%$ missing data); or

- unclear risk.

\section{Selective reporting bias. Are reports of the study free of suggestion of selective outcome reporting?}

For the included study, we described how we investigated the possibility of selective outcome reporting bias and what we found. We assessed the methods as:

- low risk (when it is clear that all of the study's pre-specified outcomes and all expected outcomes of interest to the review have been reported); 
- high risk (when not all of the study's pre-specified outcomes have been reported; one or more reported primary outcomes were not pre-specified outcomes of interest and are reported incompletely and so cannot be used; study fails to include results of a key outcome that would have been expected to have been reported); or

- unclear risk.

\section{Other sources of bias. Was the study apparently free of other problems that could put it at high risk of bias?}

For the included study, we described any important concerns we had about other possible sources of bias (e.g. whether a potential source of bias was related to the specific study design, whether the trial was stopped early owing to some data-dependent process). We assessed whether the study was free of other problems that could put it at risk of bias as:

- low risk;

- high risk; or

- unclear risk.

If needed, we planned to explore the impact of the level of bias by undertaking sensitivity analyses.

\section{WHAT'S NEW}

\begin{tabular}{lll}
\hline Date & Event & Description \\
\hline 26 February 2018 & $\begin{array}{l}\text { New citation required and conclusions } \\
\text { have changed }\end{array}$ & We made changes to the main conclusions of the original review.
\end{tabular}

26 February $2018 \quad$ New search has been performed

- We updated the search for eligible studies to February 2018.

- We found one randomised controlled trial (two publications) that was eligible for inclusion in this review (Armanian 2014).

- We included body mass index and measures of body composition in the growth parameters of the primary outcome. We also included new secondary outcome measures: long-term measures of cardio-metabolic health (such as insulin resistance, obesity, diabetes, and hypertension). These outcomes were aligned with those of the Cochrane Review titled "Multi-nutrient fortification of human milk for preterm infants" (Brown 2016).

- We applied the Grading of Recommendations Assessment, Development and Evaluation (GRADE) approach to assess the quality of evidence.

\section{H I S T O R Y}

Protocol first published: Issue 3, 1997

Review first published: Issue 2, 1999

\begin{tabular}{|c|c|c|}
\hline Date & Event & Description \\
\hline \multirow[t]{2}{*}{10 May 2002} & New search has been performed & $\begin{array}{l}\text { This is an update of the existing review: "Carbohydrate sup- } \\
\text { plementation of human milk to promote growth in preterm in- } \\
\text { fants" (Cochrane Library; } 1999, \text { Issue } 2 \text { ). }\end{array}$ \\
\hline & & $\begin{array}{l}\text { No new trials were identified in the search done in April 2002; } \\
\text { as a result, we made no substantive changes to the review. We } \\
\text { made no change to the conclusion that the addition of carbo- } \\
\text { hydrate supplements to human milk in preterm infants has not } \\
\text { been studied sufficiently to inform recommendations for prac- } \\
\text { tice. }\end{array}$ \\
\hline
\end{tabular}




\begin{tabular}{lll}
\hline Date & Event & Description \\
\hline 29 November 1998 & $\begin{array}{l}\text { New citation required and conclusions } \\
\text { have changed }\end{array}$ & Substantive amendments were made. \\
\hline
\end{tabular}

\section{CONTRIBUTIONS OF AUTHORS}

Emma Amissah assessed study eligibility, extracted data, assessed risk of bias of included studies, analysed data, interpreted results of the analysis, and updated the review. She wrote all drafts and addressed comments from co-authors.

Julie Brown assessed study eligibility, reviewed data extracted, assessed risk of bias of included studies, assisted in interpretation of analyses, and provided comments on drafts.

Jane Harding extracted data, answered queries on trial eligibility, performed risk of bias assessments of included studies, assisted in interpretation of analyses, and provided comments on all drafts of the review.

All review authors read and approved the final version of the review.

\section{DECLARATIONS OF INTEREST}

Emma Amissah: none known.

Julie Brown: none known.

Jane Harding: none known.

\section{SOURCES OF SUPPORT}

\section{Internal sources}

- Liggins Institute, The University of Auckland, Auckland, New Zealand.

\section{External sources}

- Liggins Institute, University of Auckland, New Zealand.

We acknowledge the support from the Australian and New Zealand Pregnancy and Childbirth Satellite at the Liggins Institute, University of Auckland, New Zealand

- National Institute for Health Research, UK.

Editorial support for Cochrane Neonatal has been funded with funds from a UK National Institute of Health Research (NIHR) Cochrane Programme Grant (16/114/03). The views expressed in this publication are those of the review authors and not necessarily those of the National Health Service, the NIHR, or the UK Department of Health.

- Vermont Oxford Network, USA.

Cochrane Neonatal Reviews are produced with support from Vermont Oxford Network, a worldwide collaboration of health professionals dedicated to providing evidence-based care of the highest quality for newborn infants and their families.

\section{DIFFERENCES BETWEEN PROTOCOLANDREVIEW}

The original protocol was published in 1997, and formed the basis of the last version of this review, written in 1999. This update aligned review outcomes with those of the Cochrane Review titled "Multi-nutrient fortification of human milk for preterm infants" (Brown 2016). We added body mass index and measures of body composition to growth parameters of the primary outcome. We also included new secondary outcome measures such as long-term measures of cardio-metabolic health (e.g. insulin resistance, obesity, diabetes, hypertension). We added 'Summary of findings' tables and GRADE recommendations, which were not included in the original protocol.

\section{N DEX TERMS}

\section{Medical Subject Headings (MeSH)}

*Dietary Supplements; *Infant Nutritional Physiological Phenomena; *Infant, Premature; *Milk, Human [chemistry]; Body Weight; Dietary Carbohydrates [ ${ }^{\star}$ administration \& dosage]; Enterocolitis, Necrotizing [diagnosis]; Food Intolerance [etiology]; Growth; Prebiotics [*administration \& dosage] 


\section{MeSH check words}

Humans; Infant, Newborn 